\title{
Treatment of Children and Adolescents with Epilepsy with Atomoxetine
}

\author{
Kee Jeong Park', Hyunji Ahn², Mi-Sun Yum², Tae-Sung Ko², and Hyo-Won Kim ${ }^{1 凶}$ \\ ${ }^{1}$ Department of Psychiatry, Asan Medical Center, University of Ulsan College of Medicine, Seoul, Republic of Korea \\ ${ }^{2}$ Department of Pediatric Neurology, Asan Medical Center, University of Ulsan College of Medicine, Seoul, Republic of Korea
}

Objective The objective of this study was to assess the effectiveness and safety of atomoxetine in Korean children and adolescents with epilepsy.

Methods We retrospectively reviewed the electronic medical records of 105 children and adolescents with epilepsy treated with atomoxetine. Effectiveness was measured with the Clinical Global Impressions-Severity (CGI-S) and/or Clinical Global Impressions-Improvement (CGI-I) scales at baseline, and after 4 and 12 weeks. We defined response to atomoxetine as a CGI-I score less than three at week 12. Safety was evaluated at each visit, based on clinical assessment by a child and adolescent psychiatrist and reports from participants or their caregivers.

Results In total participants ( $\mathrm{n}=105), 33$ (31.4\%) showed a response to treatment: a significant decrease in CGI-S scale score was observed over 12 weeks of atomoxetine treatment. The most common adverse event (AE) was decreased appetite ( $\mathrm{n}=16,15.2 \%)$, and life-threatening AEs were not observed. Seizure aggravation due to atomoxetine was observed in $7.6 \%(n=8)$ of total participants, and one of them discontinued atomoxetine.

Conclusion Our results provide preliminary evidence of the effectiveness and safety of atomoxetine in children and adolescents with epilepsy.

Psychiatry Investig 2020;17(5):412-416

Key Words Atomoxetine, Effectiveness, Epilepsy, Safety.

\section{INTRODUCTION}

Attention-deficit/hyperactivity disorder (ADHD) is one of the most common neurodevelopmental disorders affecting children, with a reported worldwide prevalence in childhood of $5 \%$. Inattention, hyperactivity, and impulsivity constitute its core symptoms, ${ }^{2,3}$ and children and adolescents with ADHD commonly experience behavioral problems and impaired academic and occupational achievements. ${ }^{2}$

Nearly $80 \%$ of children with epilepsy have attention problems, and one-third of children with epilepsy have a diagnosis of ADHD. ${ }^{4}$ Among children with epilepsy, the prevalence of ADHD was reported as $17-40 \%{ }^{4,5}$ Youth with epilepsy and

Received: October 24, 2019 Revised: February 11, 2020

Accepted: February 22, 2020

$\triangle$ Correspondence: Hyo-Won Kim, MD, PhD

Department of Psychiatry, Asan Medical Center, University of Ulsan College of Medicine, 88 Olympic-ro 43-gil, Songpa-gu, Seoul 05505, Republic of Korea

Tel: +82-2-3010-3414, Fax: +82-2-485-8381, E-mail: shingubi@amc.seoul.kr

(ㄷ) This is an Open Access article distributed under the terms of the Creative Commons Attribution Non-Commercial License (https://creativecommons.org/licenses/by$\mathrm{nc} / 4.0$ ) which permits unrestricted non-commercial use, distribution, and reproduction in any medium, provided the original work is properly cited. comorbid ADHD are more likely to experience academic underachievement and impaired executive function. ${ }^{6}$ Thus, identifying and managing ADHD in children with epilepsy is very important. Pharmacologic treatment has been considered as the first-line intervention for ADHD. ${ }^{7}$ Medications which are approved for $\mathrm{ADHD}$, and which could be used for the treatment of youth with epilepsy and comorbid ADHD, include atomoxetine, clonidine, and methylphenidate. ${ }^{8}$ Methylphenidate has been reported to well tolerate and effective in improving ADHD symptoms in children whose epilepsy is well controlled. ${ }^{9,10}$ However, because of possible aggravation of epilepsy, ${ }^{11}$ controversy exists about the use of methylphenidate. ${ }^{12}$ There has been limited research with other medications used to treat ADHD in childhood epilepsy. Although Torres and colleagues reported that atomoxetine did not increase seizure risk in children with ADHD and epilepsy, their study was conducted with a small population of less than thirty. ${ }^{13}$

To our knowledge, only a few studies have been performed with atomoxetine in populations with epilepsy. Therefore, we aimed to investigate the effectiveness and safety of atomoxetine in Korean children and adolescents with epilepsy. 


\section{METHODS}

\section{Participants}

We retrospectively reviewed electronic medical records from 105 patients diagnosed with epilepsy at the Department of Pediatric Neurology at Asan Medical Center, referred to the Department of Child and Adolescent Psychiatry, and then prescribed atomoxetine between June 2007 and June 2018. Participants met the following inclusion criteria: age 5-18 years; confirmed epilepsy diagnosis according to the International League Against Epilepsy Classification of Epileptic Seizures; ${ }^{14,15}$ completion of electroencephalography before atomoxetine administration; prescribed atomoxetine for longer than one week; and underwent at least one assessment for effectiveness and safety. Participants were excluded if they met one or more of the following criteria: a report by youths or their caregivers that percent of the prescribed medication taken during the study period was below $70 \%$; or a clinicianconfirmed diagnosis of a major psychiatric disorder, such as schizophrenia, other psychotic disorders, or bipolar disorder. The study was approved by the Institutional Review Board of Asan Medical Center (IRB No. 2018-0984).

\section{Assessment and measures}

One pediatric neurologist and one child and adolescent psychiatrist retrospectively reviewed data from each participant. Diagnoses of ADHD and other psychiatric disorders were assessed based on the Diagnostic and Statistical Manual of Mental Disorders, fifth edition. ${ }^{1}$

Atomoxetine effectiveness was retrospectively measured with the Clinical Global Impressions-Severity (CGI-S) ${ }^{16}$ and/ or Clinical Global Impressions-Improvement (CGI-I) scale ${ }^{16}$ at baseline, and after 4 and 12 weeks. Safety was evaluated at each visit based on clinical assessment by the child and adolescent psychiatrist and on reports from youths and caregivers. We defined response to atomoxetine as a CGI-I score less than three at week 12 .

\section{Statistical analyses}

The chi-squared test or Fisher's exact test was used for categoric variables and the independent t-test for continuous variables. We used repeated measures analysis of variance (ANO$\mathrm{VA})$ to analyze the time effect of atomoxetine treatment and mixed between-within ANOVA to compare responders and non-responders regarding atomoxetine effects on CGI-S score. Missing data were imputed by last observation carried forward. Statistical analyses were performed using Statistical Package for the Social Sciences (SPSS version 22.0; IBM Corp., Armonk, NY, USA), and statistical significance was defined as a p-value of less than 0.05 . All comparisons were two-tailed.

\section{RESULTS}

\section{Participant characteristics}

One hundred and five children and adolescents (age 9.7 \pm 3.0 years, range 5-18; 67 boys, $63.8 \%$ ) were included in the study. The mean duration and dose of entire atomoxetine treatment period were $541.6 \pm 574.3$ days (range $14-3,825$ ) and $35.9 \pm 15.5$ $\mathrm{mg} /$ day (range 10-96), respectively. The mean daily dose of atomoxetine for up to 12 weeks' treatment was $0.79 \pm 0.24 \mathrm{mg} / \mathrm{kg} /$ day (range 0.19-1.39). Atomoxetine was discontinued in $16 \mathrm{pa}-$ tients before week 12 due to: loss to follow-up ( $n=8)$; adverse events (AEs; $n=6)$; or inadequate treatment response $(n=2)$.

Overall, CGI-S scores for ADHD symptoms were significantly decreased during 12 weeks' atomoxetine treatment $[\mathrm{F}$ $(2,103)=40.025, \mathrm{p}<0.001$, partial $\eta^{2}=0.437$ ] (Figure 1). The mean CGI-S score was decreased to $4.2 \pm 0.4,3.9 \pm 0.6$, and $3.7 \pm 0.7$ at baseline, 4 week, and 12 week, respectively. For treatment responders $(n=33)$ versus non-responders $(n=72)$, significant between-group differences were evident in the main effects for time $\left[\mathrm{F}(2,101)=11,634, \mathrm{p}<0.001\right.$, partial $\left.\eta^{2}=0.187\right)$, group $\left[\mathrm{F}(1,102)=50.880, \mathrm{p}<0.001\right.$, partial $\left.\eta^{2}=0.333\right]$, and timeby-group interaction $\left[\mathrm{F}(2,101)=63.680, \mathrm{p}<0.001\right.$, partial $\eta^{2}=$ 0.558 ). The mean CGI-S score was $4.1 \pm 0.3$ at baseline, $3.5 \pm 0.6$ at 4 week, and $3.0 \pm 0.3$ at 12 week in treatment responders and that of non-responders was $4.2 \pm 0.5$ at baseline, $4.1 \pm 0.4$ at 4 week, and $4.0 \pm 0.5$ at 12 week. Similar results were also observed in the 89 participants who completed 12 weeks' atomoxetine treatment.

In total participants $(\mathrm{n}=105), 33(31.4 \%)$ were showed a treatment response. Treatment responders were significantly younger than non-responders $(\mathrm{t}=2.551, \mathrm{p}=0.013)$. There were no significant differences between treatment responders and non-responders in all other demographic and clinical characteristics (Table 1). Among the 89 participants who completed 12 weeks' atomoxetine treatment, responses to atomoxetine, and differences between treatment responders and non-re-

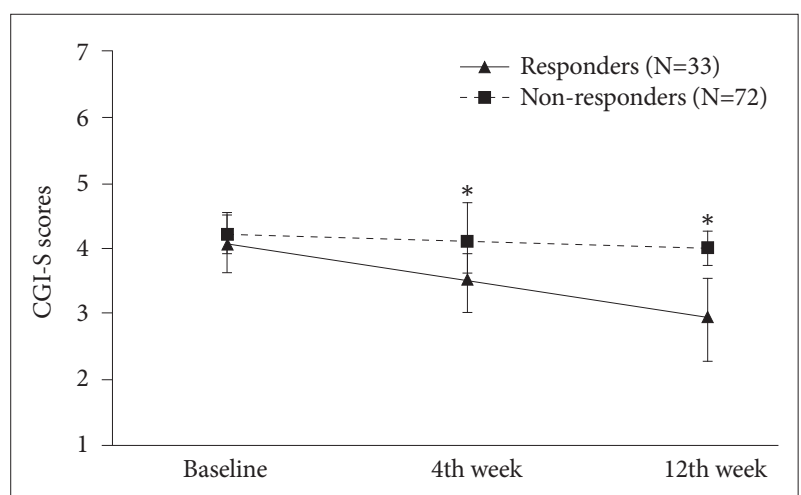

Figure 1. Comparison of mean values and standard deviations of the Clinical Global Impressions-Severity (CGI-S) scores between responders and non-responders to atomoxetine. ${ }^{*} p<0.001$. 
sponders in demographic and clinical characteristics, were similar to those in the overall study population.

AEs of the study participants are shown in Table 2. Fifty-one youths (48.6\%) experienced AEs. The most common AE was decreased appetite $(n=16,15.2 \%)$, followed by nausea/vomiting $(n=14,13.3 \%)$, seizure aggravation $(n=8,7.6 \%)$, irritability $(n=7,6.7 \%)$, insomnia $(n=6,5.7 \%)$, somnolence $(n=5,4.8 \%)$, abdominal pain $(n=4,3.8 \%)$, dizziness $(n=1,1.0 \%)$, headache

Table 1. Comparison of demographic and clinical characteristics between responders and non-responders to atomoxetine

\begin{tabular}{|c|c|c|c|c|}
\hline & $\begin{array}{c}\text { Responders } \\
(\mathrm{N}=33)\end{array}$ & $\begin{array}{c}\text { Non-responders } \\
(\mathrm{N}=72)\end{array}$ & t or $\chi^{2}$ & $\mathrm{p}$ \\
\hline Age, years, mean (SD) & $8.8(2.3)$ & $10.1(3.2)$ & -2.551 & 0.013 \\
\hline Gender, boys, N (\%) & $21(63.6)$ & $46(63.9)$ & 0.001 & 0.980 \\
\hline FSIQ, mean (SD) & $83.5(20.2)$ & $79.9(20.5)$ & 0.821 & 0.413 \\
\hline ADHD subtype, N (\%) & & & 3.680 & 0.298 \\
\hline Inattentive & $19(57.6)$ & $33(45.8)$ & & \\
\hline Hyperactive-impulsive & $2(6.1)$ & $1(1.4)$ & & \\
\hline Combined & $11(33.3)$ & $34(47.2)$ & & \\
\hline NOS & $1(3.0)$ & $4(5.6)$ & & \\
\hline \multicolumn{5}{|l|}{ Comorbid diagnosis, N (\%) } \\
\hline Mental retardation & $10(30.3)$ & $24(33.3)$ & 0.095 & 0.758 \\
\hline Mood disorder & $3(9.1)$ & $2(2.8)$ & & $0.177^{*}$ \\
\hline ODD & $0(0.0)$ & $4(5.6)$ & & $0.306^{*}$ \\
\hline Anxiety disorder & $0(0.0)$ & $5(6.9)$ & & $0.322^{*}$ \\
\hline ASD & $0(0.0)$ & $2(2.8)$ & & $1.000^{*}$ \\
\hline Tic disorder & $0(0.0)$ & $2(2.8)$ & & $1.000^{*}$ \\
\hline Trichotillomania & $0(0.0)$ & $1(1.4)$ & & $1.000^{*}$ \\
\hline Epilepsy diagnosis, N (\%) & & & 2.754 & 0.431 \\
\hline Focal epilepsy & $23(69.7)$ & $40(55.6)$ & & \\
\hline Generalized epilepsy & $7(21.2)$ & $21(292.2)$ & & \\
\hline Combined epilepsy & $0(0.0)$ & $3(4.2)$ & & \\
\hline Unknown epilepsy & $3(9.1)$ & $8(11.1)$ & & \\
\hline Etiology of epilepsy, N (\%) & & & 5.333 & 0.255 \\
\hline Structural etiology & $6(18.2)$ & $11(15.3)$ & & \\
\hline Genetic etiology & $5(15.2)$ & $17(23.6)$ & & \\
\hline Infectious etiology & $3(9.1)$ & $1(1.4)$ & & \\
\hline Metabolic etiology & $0(0.0)$ & $2(2.8)$ & & \\
\hline Unknown etiology & $19(57.6)$ & $41(56.9)$ & & \\
\hline Number of AEDs at baseline, $\mathrm{N}(\%)$ & & & 1.439 & 0.487 \\
\hline None & $5(15.2)$ & $9(12.5)$ & & \\
\hline Monotherapy & $22(66.7)$ & $42(58.3)$ & & \\
\hline Polypharmacy & $6(18.2)$ & $21(29.2)$ & & \\
\hline Uncontrolled seizure at baseline, $\mathrm{N}(\%)$ & $0(0.0)$ & $3(4.2)$ & & $0.550^{*}$ \\
\hline Seizure aggravation due to atomoxetine, N (\%) & $3(9.1)$ & $5(6.9)$ & & $0.704^{*}$ \\
\hline Previous ADHD medication, N (\%) & $3(9.1)$ & $17(23.6)$ & 3.094 & 0.079 \\
\hline Mean daily dose of atomoxetine for up to 12 week (mg/kg/day) (SD) & $0.81(0.26)$ & $0.78(0.24)$ & $<0.001$ & 0.993 \\
\hline Atomoxetine adverse event, $\mathrm{N}(\%)$ & $14(42.4)$ & $37(51.4)$ & 0.728 & 0.394 \\
\hline
\end{tabular}

Definition of response to atomoxetine was determined as less than three in CGI-I score at post-treatment. *using Fisher's exact test. ADHD: attention-deficit/hyperactivity disorder, AED: antiepileptic drug, ASD: autism spectrum disorder, FSIQ: full-scale intelligence quotient, NOS: not otherwise specified, ODD: oppositional defiant disorder, SD: standard deviation 
Table 2. Comparison of treatment emergent adverse events between responders and non-responders to atomoxetine

\begin{tabular}{lcccc}
\hline & $\begin{array}{c}\text { Responders } \\
(\mathrm{N}=33)\end{array}$ & $\begin{array}{c}\text { Non-responders } \\
(\mathrm{N}=72)\end{array}$ & $\chi^{2}$ & $\mathrm{p}$ \\
\hline Decreased appetite & 5 & 11 & $<0.001$ & 0.987 \\
Nausea/vomiting & 2 & 12 & $0.217^{*}$ \\
Seizure aggravation & 3 & 5 & $0.704^{*}$ \\
Irritability & 4 & 3 & $0.202^{*}$ \\
Insomnia & 3 & 3 & $0.376^{*}$ \\
Somnolence & 1 & 4 & $1.000^{*}$ \\
Abdominal pain & 0 & 4 & $0.306^{*}$ \\
Dizziness & 0 & 1 & $1.000^{*}$ \\
Headache & 0 & 1 & $1.000^{*}$ \\
Stuttering & 0 & 1 & $1.000^{*}$ \\
Tremor & 0 & 1 & $1.000^{*}$ \\
Chest discomfort & 0 & 1 & $1.000^{*}$ \\
Encephalopathy & 0 & 1 & $1.000^{*}$ \\
\hline
\end{tabular}

Definition of response to atomoxetine was determined as less than three in CGI-I score at post-treatment. *using Fisher's exact test. CGI-I: Clinical Global Impressions-Improvement

$(\mathrm{n}=1,1.0 \%)$, stuttering $(\mathrm{n}=1,1.0 \%)$, tremor $(\mathrm{n}=1,1.0 \%)$, chest discomfort $(n=1,1.0 \%)$ and encephalopathy $(n=1,1.0 \%)$. Among these participants who experienced AEs, six discontinued treatment before 12 week, because of AEs: gastrointestinal-related AEs (abdominal pain, nausea, and decreased appetite) in three cases, seizure aggravation in one case, irritability in one case and encephalopathy in one case.

\section{DISCUSSION}

In this study, we found that atomoxetine was effective and generally well tolerated in children and adolescents with epilepsy and comorbid ADHD. To our knowledge, this is the only study to evaluate the effectiveness and safety of atomoxetine in Korean children and adolescents with epilepsy. The response rate of atomoxetine was $31.4 \%$ in children and adolescents with epilepsy and ADHD. The most common adverse event was decreased appetite, and life-threatening AEs were not observed. Seizure aggravation due to atomoxetine was observed in about $8 \%$ of total participants, and one of them discontinued atomoxetine.

The response rates of atomoxetine have been reported as $70-85 \%$ with methylphenidate ${ }^{17}$ and $47-50 \%$ with atomoxetine $^{18,19}$ in youth with ADHD only. In a study of methylphenidate, the response rate was almost $60 \%$ in Korean children and adolescents with epilepsy and comorbid ADHD. ${ }^{9}$ However, to the best of our knowledge, response rates to atomoxetine in youths with epilepsy and comorbid ADHD have not yet been published. The response rate of atomoxetine was
$31.4 \%$ in youths with epilepsy and comorbid ADHD in the present study. As in the case of methylphenidate, the response rate of atomoxetine was lower in youths with epilepsy and comorbid ADHD than in that of children with ADHD only. The inclusion of participants with different forms of epilepsy, ${ }^{13}$ multiple antiepileptic drugs, ${ }^{13}$ and relatively short durations of treatment might have affected the lower response rate. Further prospective studies with large samples are needed.

The most common AE profiles for atomoxetine in this trial was consistent with a previous study in Korean ADHD children without epilepsy. ${ }^{20}$ The most frequently observed AEs in both trials were gastrointestinal-related AEs, including decreased appetite, nausea and vomiting. A previous study reported the incidence rates of seizure adverse events with atomoxetine between $0.1 \%$ and $0.2 \%$, and these rates were not significantly different from placebo in ADHD youth without epilepsy. ${ }^{21}$ Those results suggest that atomoxetine did not significantly affect seizure occurrence in children with ADHD only. In our study, about $8 \%$ of participants experienced seizure aggravation related to atomoxetine, and one of them discontinued atomoxetine. In a previous study for children with both epilepsy and comorbid ADHD, about $6 \%$ of participants had an increased number of seizures ${ }^{22}$ and $4 \%$ of participants had a discontinuation of atomoxetine due to exacerbation of seizure. ${ }^{13}$ The rate of seizure aggravation in our study has consistent results to a few previous studies. ${ }^{13,22}$ Seizure aggravation rates related to methylphenidate were reported as up to $20 \%$ in previous studies, ${ }^{9,23}$ and these rates are much higher than in those of atomoxetine. Our results with relatively large sample provide more reliable reference for the safety of atomoxetine and suggest that atomoxetine may be a safer treatment of ADHD than methylphenidate in children with epilepsy.

There were several limitations to our analyses. First, this study was designed as a retrospective chart review. Second, we did not compare the effectiveness and safety of atomoxetine between our participants and children without epilepsy. Third, we could not adjust for the effects of concomitant medication, including antiepileptic drugs. Fourth, we did not conduct structured interviews for the diagnosis of psychiatric disorders. Fifth, AEs may have been under-reported, as we relied on selfreporting of such events by youths or their parents/caregivers.

Despite these caveats, our results provide preliminary evidence of the effectiveness and safety of atomoxetine in Korean children and adolescents with epilepsy. Prospective studies with larger samples are needed to support these findings.

\section{Acknowledgments}

This research was supported by the Basic Science Research Program through the National Research Foundation of Korea, funded by the Ministry of Science, Information \& Communication Technology (2018R1A2B6002216). 


\section{Conflicts of Interest}

The authors have no potential conflicts of interest to disclose.

\section{Author Contributions}

Conceptualization: Hyo-Won Kim, Tae-Sung Ko, Mi-Sun Yum. Data curation: Kee Jeong Park, Hyunji Ahn. Formal analysis: Kee Jeong Park. Investigation: Hyo-Won Kim. Methodology: Hyo-Won Kim, Tae-Sung Ko, MiSun Yum. Project administration: Hyo-Won Kim. Resources: Hyo-Won Kim. Software: Hyo-Won Kim. Supervision: Hyo-Won Kim. Validation: Hyo-Won Kim. Visualization: Kee Jeong Park. Writing_original draft: Kee Jeong Park. Writing_review \& editing: Hyo-Won Kim, Tae-Sung Ko, MiSun Yum, Hyunji Ahn.

\section{ORCID iDs}

$\begin{array}{ll}\text { Kee Jeong Park } & \text { https://orcid.org/0000-0002-9709-8723 } \\ \text { Hyunji Ahn } & \text { https://orcid.org/0000-0003-0736-6585 } \\ \text { Mi-Sun Yum } & \text { https://orcid.org/0000-0003-1311-3955 } \\ \text { Tae-Sung Ko } & \text { https://orcid.org/0000-0002-8213-8964 } \\ \text { Hyo-Won Kim } & \text { https://orcid.org/0000-0002-8744-5138 }\end{array}$

\section{REFERENCES}

1. American Psychiatric Association. Diagnostic and Statistical Manual for Mental Disorder 5 (DSM-5). Arlington VA: American Psychiatric Association; 2013.

2. Barkely RA. Attention Deficit Hyperactivity Disorder: A Handbook for Diagnosis and Treatment. New York: The Guilford Press; 2015.

3. Volk HE, Neuman RJ, Todd RD. A systematic evaluation of ADHD and comorbid psychopathology in a population-based twin sample. J Am Acad Child Adolesc Psychiatry 2005;44:768-775.

4. Dunn DW, Austin JK, Harezlak J, Ambrosius WT. ADHD and epilepsy in childhood. Dev Med Child Neurol 2003;45:50-54.

5. Dunn DW, Austin JK. Differential diagnosis and treatment of psychiatric disorders in children and adolescents with epilepsy. Epilepsy Behav 2004;5(Suppl 3):S10-S17.

6. Hermann B, Jones J, Dabbs K, Allen CA, Sheth R, Fine J, et al. The frequency, complications and aetiology of ADHD in new onset paediatric epilepsy. Brain 2007;130:3135-3148.

7. Briars L, Todd T. A review of pharmacological management of attentiondeficit/hyperactivity disorder. J Pediatr Pharmacol Ther 2016;21:192206.

8. Torres AR, Whitney J, Gonzalez-Heydrich J. Attention-deficit/hyperactivity disorder in pediatric patients with epilepsy: review of pharmacological treatment. Epilepsy Behav 2008;12:217-233.

9. Park JH, Choi HW, Yum MS, Ko TS, Shon SH, Kim HW. Relationship between aggravation of seizures and methylphenidate treatment in subjects with attention-deficit/hyperactivity disorder and epilepsy. J Child Adolesc Psychopharmacol 2018;28:537-546.
10. Salpekar JA, Mishra G. Key issues in addressing the comorbidity of attention deficit hyperactivity disorder and pediatric epilepsy. Epilepsy Behav 2014;37:310-315.

11. Stevens JR, Wilens TE, Stern TA. Using stimulants for attention-deficit/hyperactivity disorder: clinical approaches and challenges. Prim Care Companion CNS Disord 2013; 15. pii: PCC.12f01472.

12. Reilly CJ. Attention deficit hyperactivity disorder (ADHD) in childhood epilepsy. Res Dev Disabil 2011;32:883-893.

13. Torres A, Whitney J, Rao S, Tilley C, Lobel R, Gonzalez-Heydrich J. Tolerability of atomoxetine for treatment of pediatric attention-deficit/hyperactivity disorder in the context of epilepsy. Epilepsy Behav 2011;20: 95-102.

14. Fisher RS, Cross JH, French JA, Higurashi N, Hirsch E, Jansen FE, et al. Operational classification of seizure types by the International League Against Epilepsy: position paper of the ILAE commission for classification and terminology. Epilepsia 2017;58:522-530.

15. Fisher RS, Cross JH, D’Souza C, French JA, Haut SR, Higurashi N, et al. Instruction manual for the ILAE 2017 operational classification of seizure types. Epilepsia 2017;58:531-542.

16. Guy W. Early Clinical Drug Evaluation Unit (ECDEU) Assessment Manual for Psychopharmacology. Washington DC: US Department of Health, Education, and Welfare Publication, National Institute of Mental Health; 1976.

17. Weiss M, Childress A, Nordbrock E, Adjei AL, Kupper RJ, Mattingly G. Characteristics of ADHD symptom response/remission in a clinical trial of methylphenidate extended release. J Clin Med 2019; 8. pii: E461.

18. Newcorn JH, Sutton VK, Weiss MD, Sumner CR. Clinical responses to atomoxetine in attention-deficit/hyperactivity disorder: the Integrated Data Exploratory Analysis (IDEA) study. J Am Acad Child Adolesc Psychiatry 2009;48:511-518.

19. Dittmann RW, Cardo E, Nagy P, Anderson CS, Adeyi B, Caballero B, et al. Treatment response and remission in a double-blind, randomized, head-to-head study of lisdexamfetamine dimesylate and atomoxetine in children and adolescents with attention-deficit hyperactivity disorder. CNS Drugs 2014;28:1059-1069.

20. Park KJ, Kim HW. Clinical and neuropsychological factors associated with treatment response and adverse events of atomoxetine in children with attention-deficit/hyperactivity disorder. J Korean Acad Child Adolesc Psychiatry 2019;30:74-82.

21. Wernicke JF, Holdridge KC, Jin L, Edison T, Zhang S, Bangs ME, et al. Seizure risk in patients with attention-deficit-hyperactivity disorder treated with atomoxetine. Dev Med Child Neurol 2007;49:498-502.

22. Hernandez J, Barragan E, Garza S. Efficacy of atomoxetine treatment in children with ADHD and epilepsy. Neuropediatrics 2006;37:THP12.

23. Ravi M, Ickowicz A. Epilepsy, attention-deficit/hyperactivity disorder and methylphenidate: critical examination of guiding evidence. J Can Acad Child Adolesc Psychiatry 2016;25:50-58. 